\title{
Design, Analysis, and Simulation of All-optical Optimized and Gate Using Y-shaped Plasmonic Waveguide for High-speed Computing Devices
}

\section{Surya Pavan Kumar Anguluri}

Godavari Institute of Engineering and Technology

\section{Srinivas Raja Banda}

Godavari Institute of Engineering and Technology

\section{Sabbi Vamshi Krishna}

Ravindra College of Engineering for Women

Sandip Swarnakar ( $\nabla$ sandipswarnakar.2008@gmail.com )

G. Pulliah College of Engineering and Technology https://orcid.org/0000-0003-3767-0916

\section{Santosh Kumar}

DIT University

\section{Research Article}

Keywords: all-optical logic gates, metal-insulator-metal waveguide, Y-combiner, linear interference, plasmonic, FDTD

Posted Date: March 22nd, 2021

DOl: https://doi.org/10.21203/rs.3.rs-327354/v1

License: (c) (i) This work is licensed under a Creative Commons Attribution 4.0 International License.

Read Full License

Version of Record: A version of this preprint was published at Journal of Computational Electronics on August 6th, 2021. See the published version at https://doi.org/10.1007/s10825-021-01748-x. 


\title{
Design, analysis, and simulation of all-optical optimized AND gate
}

\section{using Y-shaped plasmonic waveguide for high-speed computing devices}

\author{
Surya Pavan Kumar Anguluri ${ }^{1}$, Srinivas Raja Banda ${ }^{1}$, Sabbi Vamshi Krishna ${ }^{2}$, Sandip Swarnakar ${ }^{3, *}$, Santosh Kumar ${ }^{4,5}$ \\ ${ }^{1}$ Department of Electronics and Communication Engineering, Godavari Institute of Engineering \& Technology, \\ Chaitanya Knowledge City, Rajahmundry, East Godavari, Andhra Pradesh -533296, India
}

${ }^{2}$ Department of Electronics and Communication Engineering, Ravindra College of Engineering for Women, Nandikotkur Road, Kurnool, Andhra Pradesh -518452, India

${ }^{3}$ Photonics Lab, Department of Electronics and Communication Engineering, G. Pullaiah College of Engineering and Technology, Nandikotkur Road, Kurnool, Andhra Pradesh -518002, India

${ }^{4}$ Department of Electrical and Electronics \& Communication Engineering, DIT University, Dehradun 248009, Uttarakhand, India

${ }^{5}$ Shandong Key Laboratory of Optical Communication Science and Technology, School of Physics Science and Information Technology, Liaocheng University, Liaocheng - 252059, Shandong, China

*Corresponding Author's Email address: sandipswarnakar.2008@ gmail.com

\begin{abstract}
All-optical logic gates have proven their significance in the digital world using which all high-speed computations are calculated. In this paper, we have proposed a novel structure for all-optical AND using the concept of power combiner using Y-shaped metal-insulator-metal waveguide under the footprints of $4 \mu m \times 7 \mu m$. This design works under the principle of linear interference. The insertion loss and extinction ratio of the design are given by $0.165 \mathrm{~dB}$ and $14.11 \mathrm{~dB}$, respectively. The analysis of the design is carried out by finite-difference-time-domain (FDTD) method and verified using MATLAB. This minimized structure can be used to design any complex logic circuits to achieve better performance in future.
\end{abstract}

Keywords: all-optical logic gates, metal-insulator-metal waveguide, Y-combiner, linear interference, plasmonic, FDTD

\section{Introduction}

The role of communication in the day-to-day life of humans can never be replaced by any other alternative. As technology is advancing, the need for faster communication is also advancing at the same pace. Along with the speed of communication, there are several other factors to be considered while designing a device, like the cost of the individual circuit, size of the device, power handling capacity, heat dissipation issues, and interconnect delays [1]. The first generation of electronics is based on semiconductor technology which makes use of vacuum tube-based transistors for logical operations but is less preferred due to its high heat dissipation and interconnects delay [2]. These limitations are somewhat mitigated by the next technology called photonics [3-4]. In this field, instead of electrons, photons are used to exchange information [5]. But the optical devices suffer diffraction limit when the size of the device is closer to the operation wavelength [6]. Also, the size of optical components is nearly 1000 times greater than the electronic devices which adds another drawback to it [7]. The next generation of technology came with a new proposal called surface plasmons, where the optical signal interacts with the metallic structures at a nano-scale giving a new branch called plasmonic [8-9]. It is the combined effect of a miniaturized version of electronics and the capacity of photonics [10]. When light of a certain wavelength is incident on the metal surface, the free electrons are excited by absorbing the energy 
from light and are bonded at the interface of metal and dielectric [11]. These surface plasmon polaritons (SPPs) are capable of eliminating the diffraction limit in photonics [7, 11-14]. These SPPs can able to confine and control the light beyond the diffraction limit and the losses inside the SPs can be overcome by using different waveguides like metalinsulator-metal (MIM) [15-16], insulator-metal-insulator (IMI), dielectric-loaded surface plasmon polariton waveguide (DLSPPW) [14, 17-24]. Among these, the MIM waveguide is best suited because of its capacity to confine light to deep sub-wavelength [2, 16]. Logic gates are the basic building blocks of all digital circuits. Several optical devices like directional coupler (DC), Mach-Zehnder-Interferometer (MZI), power combiners, power splitters are used to realize the several logic gates like AND, OR, NOT, XOR, XNOR, and the universal gates like NAND and NOR [25-32, 45]. These all-optical logic gates hence are used to design all the combinational circuits like multiplexers, demultiplexers, code converters, adders and subtractors, parity generators [33-41]. In this paper, a minimized design of all-optical AND gate based on power combiner using Y-shaped waveguide is proposed and verified using FDTD method [42]. Section 2 will describe the design of Y-combiner followed by design of AND gate. The simulation results are provided in Section 3. Section 4 includes a result analysis where the present work is compared with previously reported works and Section 5 gives the conclusion of the proposed design.

\section{Design of AND gate using Y-Combiner}

In this paper, the proposed design of AND gate using Y-combiner works on the principle of linear interference [43]. The inputs applied to the arms of the power combiner are controlled by an external phase shifter to obtain the desired output of the logical AND gate. The Y-combiner is designed using the S-bend sine waveguide whose equation is defined as

$$
y(t)=\frac{D-2 * W}{4}+\frac{D}{4} \cos \left(\frac{\pi t}{L}\right)
$$

where $\mathrm{D}$ is the input separation gap between two arms of a combiner, $\mathrm{W}$ is the width of the waveguide and $\mathrm{L}$ is the length of the S-Bend-shaped waveguide. The waveguide is structured using Eq. 1, as shown in Fig. 1.

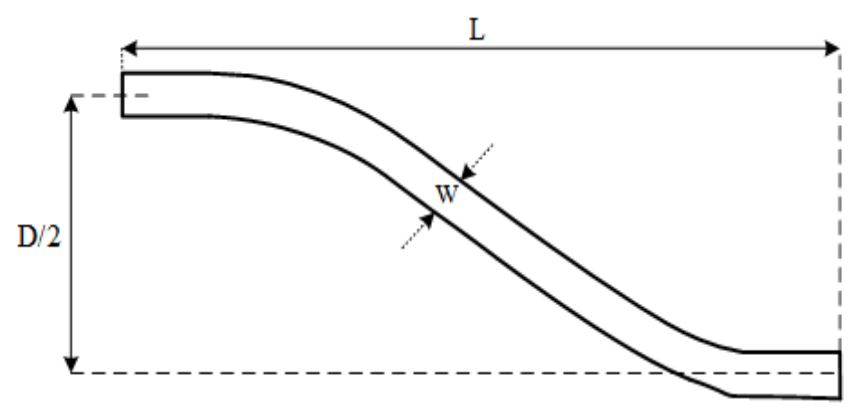

Fig. 1: Structure of S-bend sine waveguide

Another waveguide of S-bend shape is arranged symmetrically along the $\mathrm{X}$-axis to obtain the actual Y-combiner. In this paper, the all-optical AND gate has been designed using the concept of power combiner with the help of a Yshaped waveguide. The design of the Y-combiner is achieved by combining the two symmetrical S-bend structures joined at one end to form a Y-shape structure as shown in Fig. 2. 


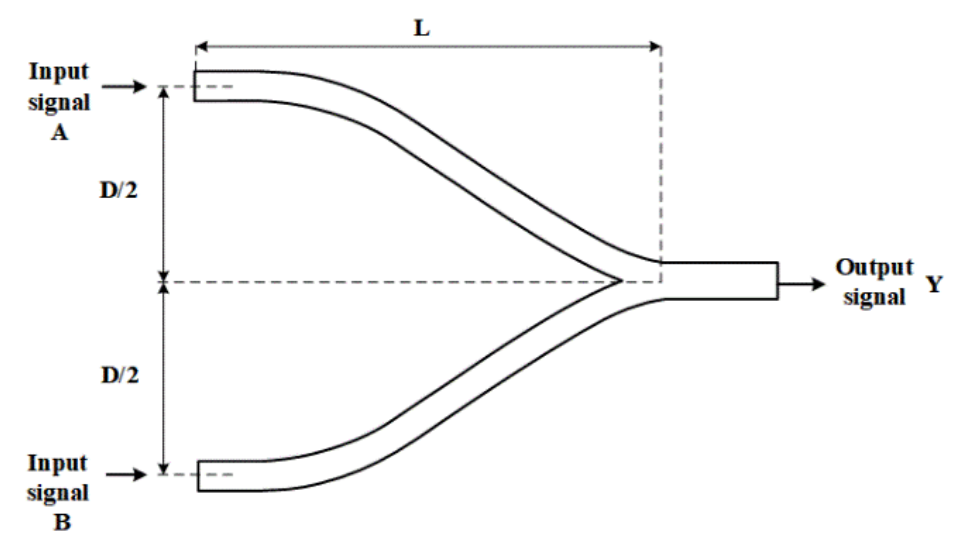

Fig. 2: Schematic of symmetric Y-combiner

The above structure is designed using the plasmonic waveguide by keeping refractive index as 2.1. The final minimized structure is obtained as a result of altering the parameters of the Y-combiner like S-bend length, Input separation gap, and the length of the linear waveguide.

Table. 1: Extinction ratio values for various S-bend lengths of Y-combiner

\begin{tabular}{|c|c|c|c|c|}
\hline Sl. No. & $\begin{array}{c}\text { S bend length } \\
(\boldsymbol{\mu m})\end{array}$ & PoN & PofF & $\begin{array}{c}\text { Extinction Ratio } \\
(\mathbf{d B})\end{array}$ \\
\hline 1 & 4.3 & 1.9668 & 0.0916 & 13.31 \\
\hline 2 & 4.2 & 1.9516 & 0.0903 & 13.34 \\
\hline 3 & 4.1 & 1.9462 & 0.0889 & 13.40 \\
\hline 4 & 4 & 1.9156 & 0.0878 & 13.38 \\
\hline 5 & 3.9 & 1.9300 & 0.0869 & 13.47 \\
\hline 6 & 3.8 & 1.9267 & 0.0871 & 13.44 \\
\hline 7 & 3.7 & 1.9250 & 0.0879 & 13.40 \\
\hline 8 & 3.6 & 1.9099 & 0.0879 & 13.37 \\
\hline
\end{tabular}

By keeping the input separation gap at $3 \mu \mathrm{m}$, various parameters like peak output power at ON state, peak output power at OFF state, Y-angle, and the ER are calculated by varying the S-bend length and are tabulated. From Table. 1, it is found that the ER is the maximum at S-bend length of $3.9 \mu \mathrm{m}$ and its value is $13.47 \mathrm{~dB}$. A plot of S-bend length versus ER is shown in Fig. 3.

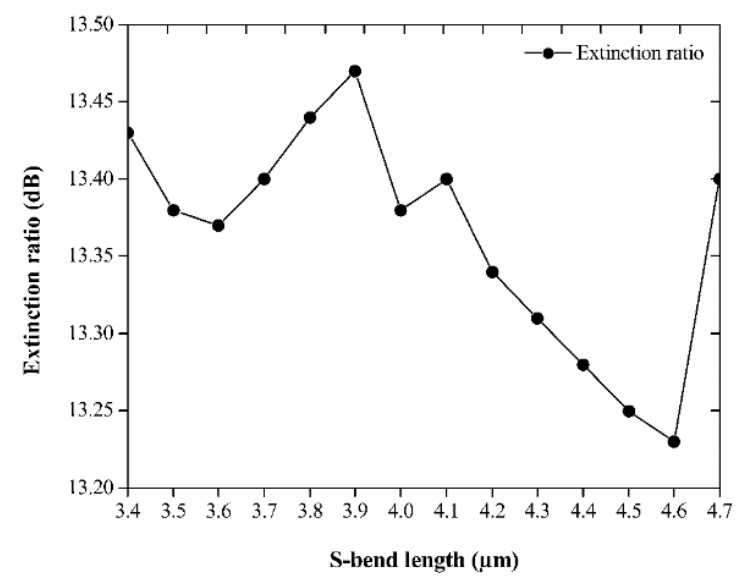

Fig. 3: Plot of S-bend length versus extinction ratio at $\mathrm{D}=3 \mu \mathrm{m}$ 
Similarly, the mentioned parameters are calculated by varying the input separation gap by keeping the S-bend length constant at $\mathrm{L}=3.9 \mu \mathrm{m}$ and the values are mentioned in Table 2 .

Table. 2: Extinction ratio values for various Input separation gaps at $\mathrm{L}=3.9 \mu \mathrm{m}$

\begin{tabular}{|c|c|c|c|c|}
\hline S. No. & D & PoN & Poff & Extinction ratio (dB) \\
\hline 1 & 3.2 & 1.9109 & 0.0884 & 13.34 \\
\hline 2 & 3.1 & 1.9425 & 0.0888 & 13.39 \\
\hline 3 & 3.0 & 1.9300 & 0.0869 & 13.46 \\
\hline 4 & 2.9 & 1.9401 & 0.0851 & 13.57 \\
\hline 5 & 2.8 & 1.9905 & 0.0873 & 13.58 \\
\hline 6 & 2.7 & 2.0181 & 0.0883 & 13.59 \\
\hline 7 & 2.6 & 2.0307 & 0.0883 & 13.62 \\
\hline 8 & 2.5 & 2.0585 & 0.0895 & 13.61 \\
\hline
\end{tabular}

From Table. 2, at the value of $\mathrm{D}=2.6 \mu \mathrm{m}$, the ER is found to be greater than the previously noted value and it is 13.62 dB. A graphical representation of input separation gap versus ER is shown in Fig. 4.

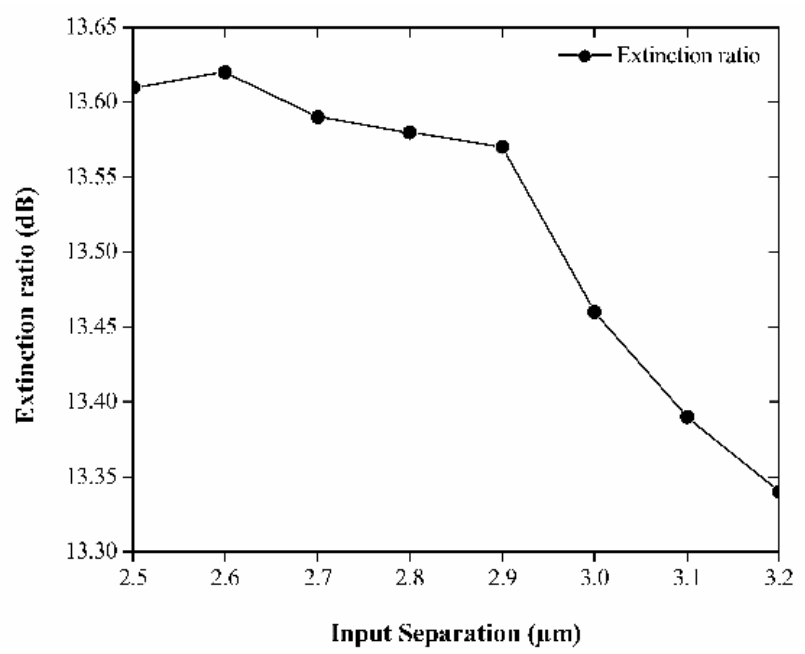

Fig. 4: Plot of input separation gap versus extinction ratio at $\mathrm{L}=3.9 \mu \mathrm{m}$

The S-bend length and the input separation gap are kept constant at $3.9 \mu \mathrm{m}$ and $2.6 \mu \mathrm{m}$, respectively and the length of the linear waveguide is modified to attain the maximum extinction ratio. The ER at various lengths of linear waveguide is shown in Table. 3.

Table. 3: Extinction ratio values for various lengths of linear waveguide

\begin{tabular}{|c|c|c|c|c|}
\hline S. No. & Linear & PoN & PoFf & Extinction ratio (dB) \\
\hline 1 & 3.1 & 2.0307 & 0.0883 & 13.62 \\
\hline 2 & 3 & 2.0526 & 0.0807 & 14.05 \\
\hline 3 & 2.9 & 2.0775 & 0.0806 & 14.11 \\
\hline 4 & 2.8 & 2.0781 & 0.0813 & 14.07 \\
\hline 5 & 2.7 & 2.0845 & 0.0815 & 14.07 \\
\hline 6 & 2.6 & 2.0865 & 0.0815 & 14.08 \\
\hline
\end{tabular}




\begin{tabular}{|l|l|l|l|l|}
\hline 7 & 2.5 & 2.0941 & 0.0928 & 13.53 \\
\hline 8 & 2.4 & 2.0956 & 0.0938 & 13.49 \\
\hline
\end{tabular}

The ER is found to be larger at the linear waveguide length of $2.9 \mu \mathrm{m}$ which is $14.11 \mathrm{~dB}$, significantly greater than already obtained values. A plot of linear waveguide length versus ER is shown in Fig. 5.

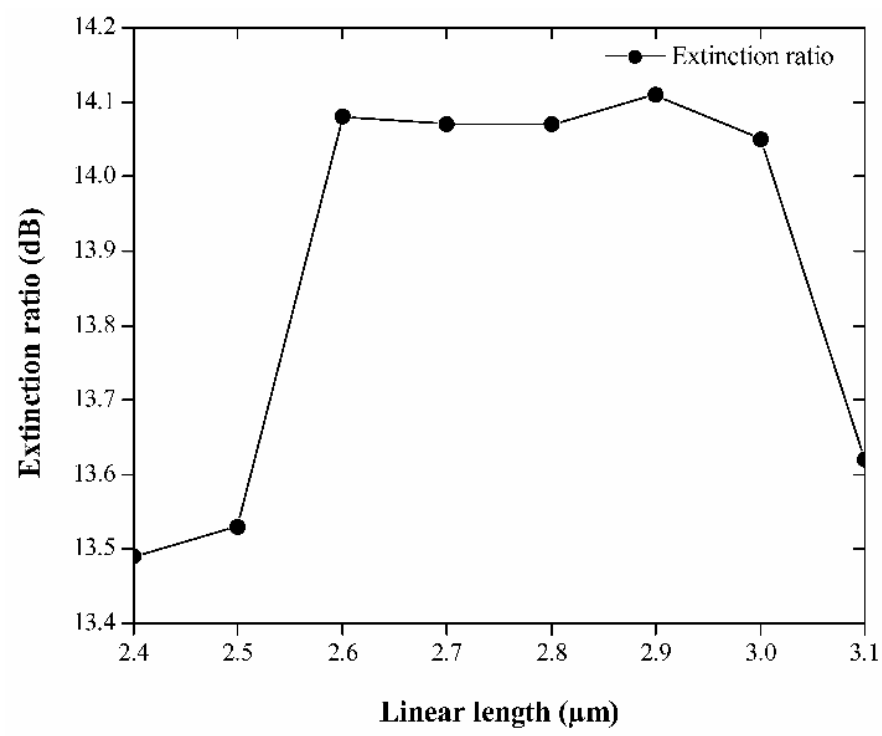

Fig. 5: Plot of linear waveguide length versus extinction ratio at $L=3.9 \mu \mathrm{m}$ and $\mathrm{D}=2.6 \mu \mathrm{m}$

The final dimensions of the Y-combiner at which the maximum ER is obtained are depicted in Table. 4.

Table. 4: Design parameters of AND gate using Y-combiner

\begin{tabular}{|c|l|c|}
\hline S. No & \multicolumn{1}{|c|}{ Parameter } & Value \\
\hline 1 & S-bend length (L) & $3.9 \mu \mathrm{m}$ \\
\hline 2 & Input separation (D) & $2.6 \mu \mathrm{m}$ \\
\hline 3 & Linear length & $2.9 \mu \mathrm{m}$ \\
\hline 4 & Refractive index of waveguide & 2.1 \\
\hline 5 & Width of the waveguide & $0.25 \mu \mathrm{m}$ \\
\hline
\end{tabular}

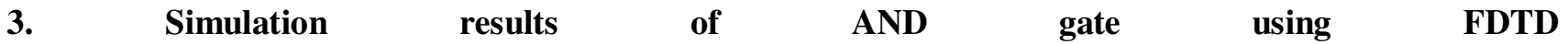

The minimized design of logical AND gate has been verified using MATLAB and FDTD. The analysis of the structure is carried out with the help of FDTD method. A continuous wave of $1550 \mathrm{~nm}$ is applied at both the input terminals of Ycombiner. The input optical signals with the power of $1 \mathrm{e}^{9} \mathrm{~W} / \mathrm{m}$ and $3 \mathrm{e}^{9} \mathrm{~W} / \mathrm{m}$ are considered as the low and high optical intensity signals. The entire simulation is carried out in the Transverse Electric (TE) mode of the plasmonic waveguide, excited by the source with Gaussian wave for both inputs. The simulation parameters of the proposed design are given in Table. 5.

Table. 5: Simulation parameters of the AND gate using Y-combiner

\begin{tabular}{|l|l|}
\hline Parameter & Value \\
\hline Type of polarization & TE \\
\hline
\end{tabular}




\begin{tabular}{|l|l|}
\hline Wavelength & $1.55 \mu \mathrm{m}$ \\
\hline Mesh size $\mathrm{X}(\mu \mathrm{m})$ & 0.0114 \\
\hline Mesh size Z $(\mu \mathrm{m})$ & 0.0114 \\
\hline No. of mesh cells X & 349 \\
\hline No. of mesh cells Z & 603 \\
\hline $\begin{array}{l}\text { Input field transverse } \\
\text { Low-intensity signal } \\
\text { power }\end{array}$ & $1 \mathrm{e}^{9} \mathrm{~W} / \mathrm{m}$ \\
\hline $\begin{array}{l}\text { High-intensity signal } \\
\text { power }\end{array}$ & $3 \mathrm{e}^{9} \mathrm{~W} / \mathrm{m}$ \\
\hline
\end{tabular}

As shown in the truth table of AND gate in Table. 6, the output of the AND gate is high when both of the inputs are high, otherwise, it is low. The timing diagram of AND gate is shown in Fig. 6, is verified using MATLAB; where the two input signals A and B are represented by first and second row and the last row represents the output of logical AND gate.

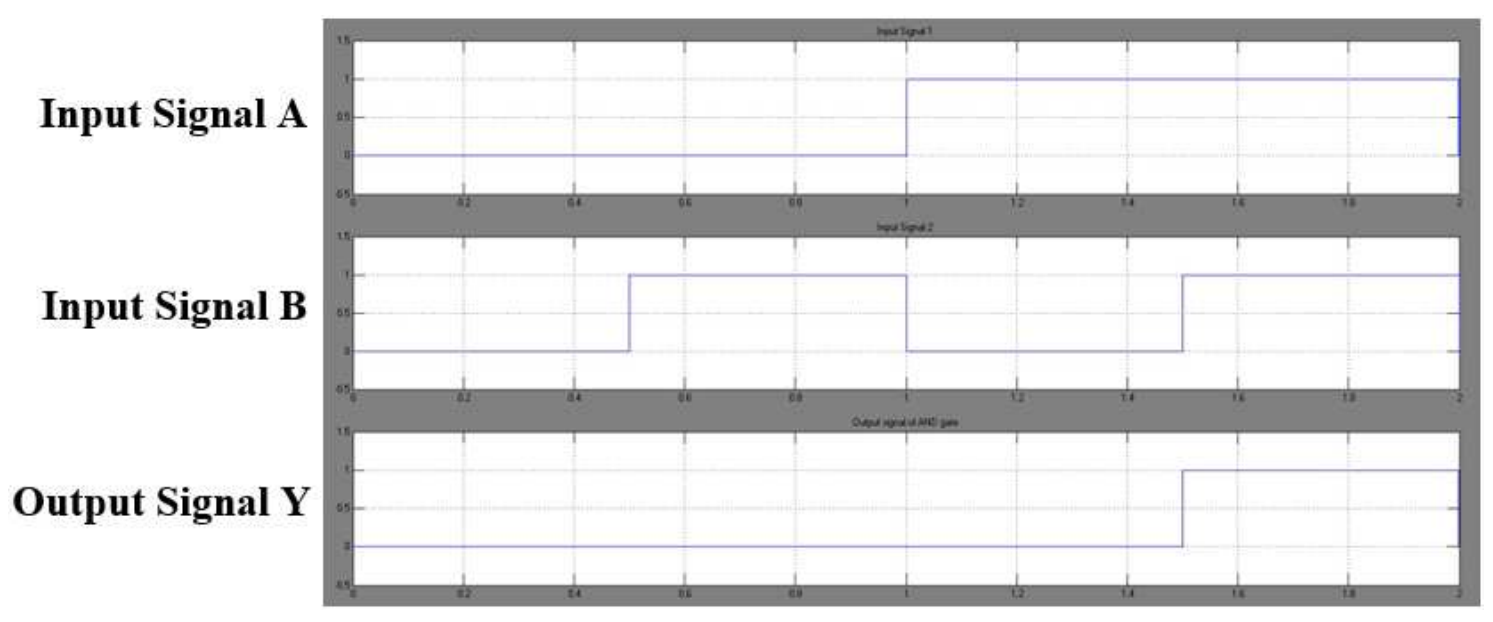

Fig. 6: The timing diagram of AND gate using MATLAB

\section{Case 1: when $A=0$ and $B=0$}

In this case, two inputs of the Y-combiner are given a low-intensity signal of power $1 e^{9} \mathrm{~W} / \mathrm{m}$. According to the truth table of AND gate, the output power is low. A phase difference of $180^{\circ}$ is created between the two input signals. Since two input signals are having the same amplitude and are out of phase, destructive interference will occur and the output of AND gate is low $(\mathrm{Y}=0)$

\section{Case 2: when $A=0$ and $B=1$}

In this case, the upper arm of combiner is provided with the low-intensity signal $\left(1 e^{9} \mathrm{~W} / \mathrm{m}\right)$ and the lower arm of the combiner is given the high-intensity signal $\left(3 e^{9} \mathrm{~W} / \mathrm{m}\right)$. A phase shift of $180^{0}$ is introduced between the two input signals. Similarly, in case of $\mathrm{A}=0$ and $\mathrm{B}=0$, destructive interference will occur which in turn reduces the intensity of output signal. Hence the output of the AND gate is low $(\mathrm{Y}=0)$. The optical field propagation for logic ' $0 \& 1$ ' is shown in Fig. 7(a). 


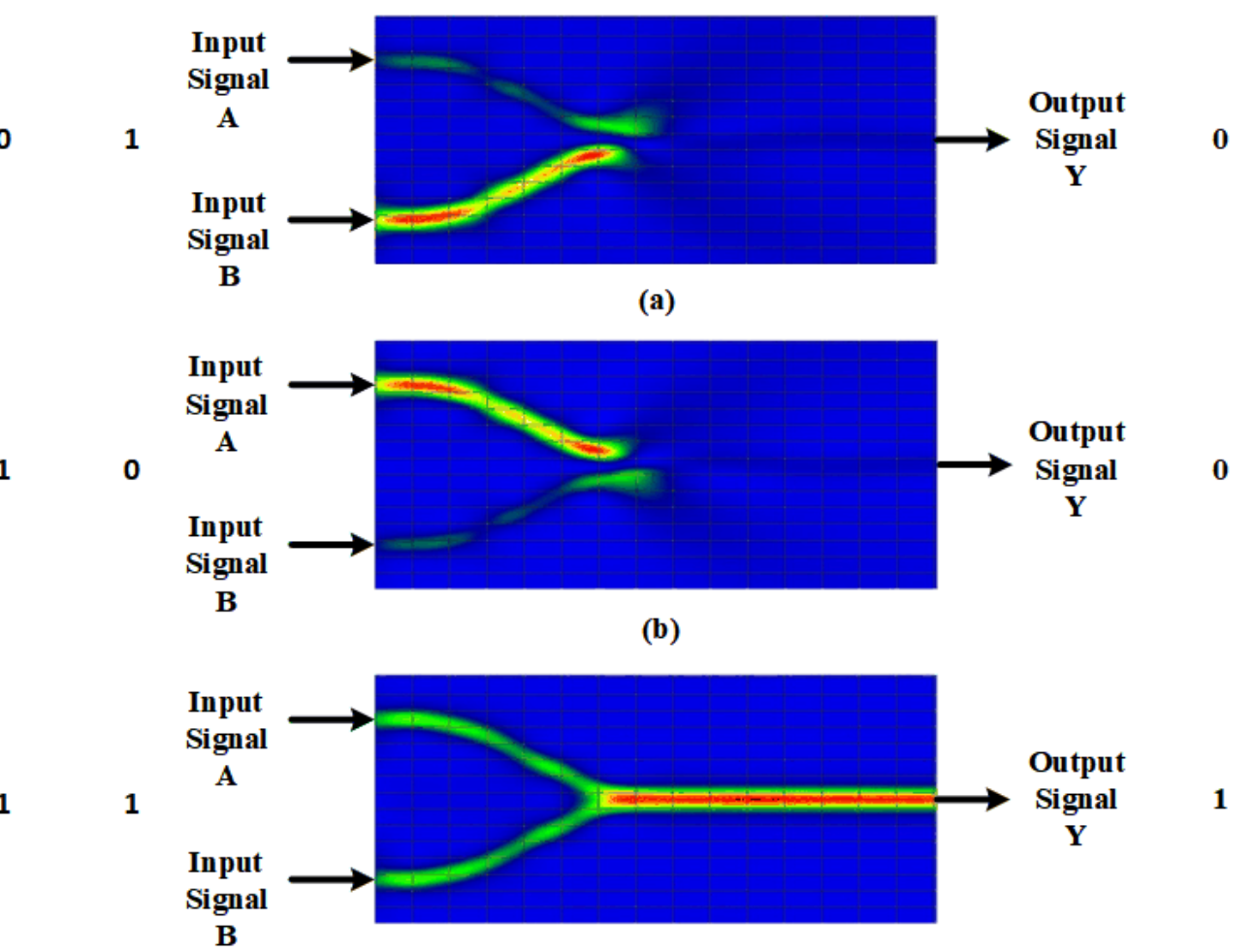

(c)

Fig. 7: Light propagation through proposed AND gate for all combinations of input signals using FDTD method

\section{Case 3: when $A=1$ and $B=0$}

Unlike the previous case, here the upper arm of the combiner is provided with the high-intensity signal $\left(3 e^{9} \mathrm{~W} / \mathrm{m}\right)$ and the lower arm is supplied with the low-intensity signal $\left(1 e^{9} \mathrm{~W} / \mathrm{m}\right)$. Thereby due to the similar amplitudes of the input signals and out of phase $\left(180^{\circ}\right)$, again the destructive interference will make the output of AND gate to low $(\mathrm{Y}=0)$. The optical field propagation for logic ' 1 \& 0 ' is shown in Fig. 7(b).

\section{Case 4: when $A=1$ and $B=1$}

In this case, both the input ports of the power combiner are supplied with a high-intensity signal $\left(3 e^{9} \mathrm{~W} / \mathrm{m}\right)$. Here the phase difference between the signals is made to $0^{0}$. According to the principle of Constructive interference, when two signals are having the same amplitude and same phase difference, then the intensity of output signal will be twice the input signal intensity ( $\mathrm{Y}=1)$. The optical field propagation for logic ' 1 and 1' is shown in Fig. 7(c).

All the input combinations along with phase values are shown in Table. 6.

Table. 6: Truth table for AND gate along with phase and transmission efficiency

\begin{tabular}{|c|c|c|c|c|c|c|}
\hline \multicolumn{5}{|c|}{ Inputs } & \multicolumn{2}{|l|}{ Output } \\
\hline$\overline{\mathbf{A}}$ & $\overline{\mathbf{B}}$ & Input phase $A$ & Input phase B & Phase Difference & Transmission efficiency & (A.B) \\
\hline 0 & 1 & $180^{\circ}$ & $0^{0}$ & $180^{\circ}$ & $19.67 \%$ & 0 \\
\hline 1 & 0 & $180^{\circ}$ & $0^{0}$ & $180^{\circ}$ & $21.64 \%$ & 0 \\
\hline 1 & 1 & $0^{0}$ & $0^{0}$ & $0^{0}$ & $152.6 \%$ & 1 \\
\hline
\end{tabular}

\section{Result analysis}


In this paper, the suggested device is in the footprints of $7 \mu \mathrm{m} \times 4 \mu \mathrm{m}$. The performance parameters like insertion loss and extinction ratio are calculated using the output results. The Insertion Loss is given by

$$
\text { Insertion Loss }(\mathrm{IL})=10 \log _{10}\left(\frac{P_{\text {out }}}{P_{\text {in }}}\right) \text {, }
$$

where $\mathrm{P}_{\text {out }}$ is the peak output power, $\mathrm{P}_{\text {in }}$ is the peak input power.

The Extinction Ratio is defined as

$$
\text { Extinction Ratio }(\mathrm{ER})=10 \log _{10} \frac{\left(P_{\text {out }} \mid O N\right)}{\left(P_{\text {out }} \mid \text { OFF }\right)}
$$

where $P_{\text {out }} \mid O N$ is output optical power in ON state, $P_{\text {out }} \mid O F F$ is output optical power in OFF state.

The IL and ER of our work are found to be $0.165 \mathrm{~dB}$ and $14.11 \mathrm{~dB}$ respectively. For better performance of logic gates, the insertion loss should be low and the Extinction ratio should be high as possible [44]. This paper work is compared with the previously published works in following parameters as shown in the Table. 7.

\begin{tabular}{|c|c|c|c|c|c|c|c|c|c|}
\hline $\begin{array}{l}\text { Sr. } \\
\text { No } \\
\text {. }\end{array}$ & $\begin{array}{c}\text { Material } \\
\text { used }\end{array}$ & $\begin{array}{c}\text { Extinctio } \\
\text { n ratio }\end{array}$ & $\begin{array}{c}\text { Wavelengt } \\
h\end{array}$ & $\begin{array}{c}\text { Design } \\
\text { footprint } \\
\mathrm{S}\end{array}$ & $\begin{array}{c}\text { Refractiv } \\
\text { e index }\end{array}$ & $\begin{array}{c}\text { Low- } \\
\text { intensity }\end{array}$ & $\begin{array}{c}\text { High- } \\
\text { intensity }\end{array}$ & Structure & Ref. \\
\hline 1 & $\begin{array}{c}\text { Plasmonic } \\
\text { MIM } \\
\text { waveguide }\end{array}$ & - & $1550 \mathrm{~nm}$ & - & - & $\begin{array}{c}4.45 \mathrm{e}^{8} \mathrm{~W} / \\
\mathrm{m}\end{array}$ & $\begin{array}{c}4.45 \mathrm{e}^{9} \mathrm{~W} / \\
\mathrm{m}\end{array}$ & $\begin{array}{c}3 \text { MZIs } \\
\text { and } 2 \\
\text { Splitters }\end{array}$ & [2] \\
\hline 2 & $\begin{array}{l}\text { 2-D } \\
\text { photonic } \\
\text { crystals }\end{array}$ & $8.47 \mathrm{~dB}$ & $1550 \mathrm{~nm}$ & - & 3.4 & - & - & $\begin{array}{c}21 \times 21 \\
\text { array of Si } \\
\text { rods }\end{array}$ & [25] \\
\hline 3 & $\begin{array}{l}\text { Surface } \\
\text { plasmon } \\
\text { polaritons }\end{array}$ & - & $800 \mathrm{~nm}$ & $\begin{array}{l}10 \mu \mathrm{m} \\
\times 20 \mu \mathrm{m}\end{array}$ & 1.52 & - & - & $\begin{array}{c}\text { Two } \\
\text { crossed } \\
\text { linear } \\
\text { waveguide } \\
\mathrm{s}\end{array}$ & [26] \\
\hline 4 & $\begin{array}{l}\text { 2-D } \\
\text { photonic } \\
\text { crystals }\end{array}$ & - & $1550 \mathrm{~nm}$ & $\begin{array}{l}10 \mu \mathrm{m} \\
\times 10 \mu \mathrm{m}\end{array}$ & 3.4 & - & - & $\begin{array}{c}16 \times 17 \\
\text { array of } \mathrm{Si} \\
\text { rods }\end{array}$ & [32] \\
\hline 5 & $\begin{array}{l}\text { Nanoring } \\
\text { IMI } \\
\text { plasmonic } \\
\text { waveguide } \\
\text { s }\end{array}$ & - & $1550 \mathrm{~nm}$ & $\begin{array}{l}400 \mathrm{~nm} \\
\times 400 \mathrm{~nm}\end{array}$ & 1.357 & - & - & $\begin{array}{l}3 \text { Straight } \\
\text { stripes and } \\
2 \text { nano- } \\
\text { ring } \\
\text { resonators }\end{array}$ & [38] \\
\hline 6 & $\begin{array}{l}\text { Plasmonic } \\
\text { MIM } \\
\text { waveguide }\end{array}$ & - & $\begin{array}{c}900 \mathrm{~nm} \& \\
1330 \mathrm{~nm}\end{array}$ & - & 1.357 & - & - & $\begin{array}{c}3 \text { slot and } \\
4 \text { nano- } \\
\text { rings }\end{array}$ & [45] \\
\hline 7 & $\begin{array}{l}\text { Plasmonic } \\
\text { MIM } \\
\text { waveguide }\end{array}$ & $14.11 \mathrm{~dB}$ & $1550 \mathrm{~nm}$ & $\begin{array}{l}7 \mu m \\
\times 4 \mu m\end{array}$ & 2.1 & $2 \mathrm{e}^{8} \mathrm{~W} / \mathrm{m}$ & $3 \mathrm{e}^{9} \mathrm{~W} / \mathrm{m}$ & $\begin{array}{l}\text { One Y- } \\
\text { combiner }\end{array}$ & $\begin{array}{c}\text { This } \\
\text { Wor } \\
k\end{array}$ \\
\hline
\end{tabular}

Table. 7: Comparison of a proposed device with existing one 


\section{Conclusion}

In this work, an all-optical AND logic gate is designed with the help of a Y-shaped plasmonic MIM waveguide. The design is in the area of $4 \times 7 \mu \mathrm{m}^{2}$ which is smaller when compared to the previous works. The key parameters like insertion loss and extinction ratio are calculated. The IL and ER of our work are found to be $0.165 \mathrm{~dB}$ and $14.11 \mathrm{~dB}$ respectively. The design parameters like S-bend length, input separation gap, and linear waveguide are optimized to obtain the maximum extinction ratio and to minimize the losses inside the waveguide. Due to simple structure and controllability, the Y-combiner based AND gate can provide a new method to implement logic functions in digital electronics. This design has a minimized structure and is also used in future works to design ultra-compact devices for fast optical computing.

\section{Acknowledgment}

This work was supported by the Science and Engineering Research Board, India [grant number: TAR/2018/000051].

\section{Disclosure}

The authors declare that there are no conflicts of interest related to this article.

\section{References}

1. Cotter, D., Manning, R.J., Blow, K.J., Ellis, A.D., Kelly, A.E., Nesset, D., Phillips, I.D., Poustie, A.J., Rogers, D.C.: Nonlinear Optics for High-Speed Digital Information Processing. Sci. 286(54444), 1523-1528 (1999)

2. Kumar S., Singh L.: Proposed new approach to design all-optical AND gate using plasmonic-based Mach-Zehnder interferometer for high-speed communication. Proc. SPIE., Nanophotonics VI. 9884, 1-7 (2016)

3. Tang Y., Zeng X., Liang J.: Surface plasmon resonance: an introduction to a surface spectroscopy technique. J. Chem. Educ. 87(7) 742-746 (2010)

4. Holmgaard T., Bozhevolnyi S.I.: Theoretical Analysis of Dielectric-loaded Surface Plasmon-polariton Waveguides. Phys. Rev. B. 75(24), 1-12 (2007)

5. Wu, Y.D.: Nonlinear all-optical switching device by using the spatial soliton collision. Fib. and Int. Opt. 23, 387-404 (2004)

6. Kumar S., Singh L., Chen, N.K.: (2016) Design of All-Optical Universal Gates Using Plasmonics Mach-Zehnder Interferometer for WDM Applications. Plasmonics. 13, 1277-1286 (2018)

7. Ozbay E.: Plasmonics: Merging Photonics and Electronics at Nanoscale Dimensions. Sci. 311(5758), 189-193 (2006)

8. Gibbs, H.M.: Optical bistability: Controlling Light with Light. Academic, New York (1985)

9. Hu, X., Jiang, P., Ding, C., Yang, H., Gong, Q.: Picosecond and low-power all-optical switching based on an organic photonic-bandgap microcavity. Nat. Photon. 2(3), 185-189 (2008)

10. Hayashi, S., Okamoto T.: Plasmonics: visit the past to know the future. J. Phys. D: Appl. Phys. 45, 1-24 (2012)

11. Barnes, W.L., Dereux, A., Ebbesen, T.W.: Surface plasmon subwavelength optics. Nature. 424, 824-830 (2003)

12. Zhang, Q., Huang, X.G., Lin, X.S., Tao, J., Jin, X.P. A subwavelength coupler-type MIM optical filter. Opt. Exp. 17(9), 7549-7554 (2009)

13. Talebi, N., Mahjoubfar, A., Shahabadi, M.: Plasmonic ring resonator, J. Opt. Soc. Am. B 25(12) 2116-2122 (2008)

14. Gramotnev, D.K., Bozhevolnyi, S.I.: Plasmonics beyond the diffraction limit. Nat. Photon. 4, 83-91 (2010) 
15. Khan, S.A., Chang, C.M., Zaidi, Z., Shin, W., Shi, Y., Bowden, A.K.E., Solgaard, O.: Metal-insulator-metal waveguides for particle trapping and separation. Lab on a Chip. 16(12), 2302-2308 (2016)

16. Armacost, M., Augustin, A., Felsner, P., Feng, Y., Friese, G., Heidenreich, J., Hueckel, G., Prigge, O., Stein, K.: A high reliability metal insulator metal capacitor for $0.18 \mu \mathrm{m}$ copper technology. IEDM Tech. Dige. IEEE Conf. CA, USA 157-160 (2000) https://doi.org/10.1109/IEDM.2000.904282

17. Feng, N., Brongersma, M.L., Negro, L.D.: Metal - Dielectric Slot-Waveguide Structures for the Propagation of Surface Plasmon Polaritons at 1. $55 \mu \mathrm{m}$. IEEE J. of Quant. Electron. 43(6), 479-485 (2007)

18. Singh, A., Pal, A., Singh, Y., Sharma, S.: Design of optimized all-optical NAND gate using metal-insulator-metal waveguide. Optik. 182, 524-528 (2019)

19. Zia, R., Schuller, J.A., Chandran, A., Brongersma, M.L.: Plasmonics: the next chip-scale technology. Materialstoday 9(7-8), 20-27 (2006)

20. Dionne, J.A., Sweatlock, L.A., Atwater, H.A., Polman, A.: Plasmon slot waveguides: Towards chip-scale propagation with subwavelength-scale localization. Phys. Rev. B 73(3), 035407 Proc. of SPIE. 9884, 98842D-6 (2006)

21. Pile, D.F., Ogawa, T., Gramotnev, D.K., Matsuzaki, Y., Vernon, K.C., Yamaguchi, K., Okamoto, T., Haraguchi, M., Fukui, M.: Two-dimensionally localized modes of a nanoscale gap plasmon waveguide. Appl. Phys. Lett. 87(26), 1-3 (2005)

22. Chen, Z., Holmgaard, T., Bozhevolnyi, S.I., Krasavin, A.V., Zayats, A.V., Markey, L., Dereux, A.: Wavelengthselective directional coupling with dielectric-loaded plasmonic waveguides. Opt. Lett. 34(3), 310-312 (2009)

23. Charbonneau, R., Lahoud, N., Mattiussi, G., Berini, P.: Demonstration of integrated optics elements based on longranging surface plasmon polaritons. Opt. Exp. 13(3), 977-984 (2005)

24. Jung, J.H.: Optimal design of dielectric-loaded surface plasmon polariton waveguide with genetic algorithm. J. of the Opt. Soc. of Korea. 14(3), 277-281 (2010)

25. Rao, D.G.S., Swarnakar, S., Palacharla, V., Raju, K.S.R., Kumar, S.: Design of all-optical AND, OR, and XOR logic gates using photonic crystals for switching applications, Photon. Netw. Commun. 41, 109-118 (2021)

26. Birr, T., Zywietz, U., Chhantyal, P., Chichkov, B.N., Reinhardt C.: Ultrafast surface plasmon-polariton logic gates and half-adder. Opt. Exp. 23(25), 31755-31765 (2015)

27. Fakhruldeen, H.F., Mansour, T.S.: All-Optical NOT Gate Based on Nanoring Silver-Air Plasmonic Waveguide. Int. J. of Engg. \& Tech. 7(4), 2818-2821 (2018)

28. Gogoi, N., Sahu P.P.: Design of All-optical Inverter using Nonlinear Plasmonic Two-mode Waveguide. Adv. Res. in Elect. and Electron. Engg. 2(11), 35-38 (2015)

29. Nozhat N., Alikomak H., Khodadadi M.: All-optical XOR and NAND logic gates based on plasmonic nanoparticles. Opt. Commun. 392, 208-213 (2017)

30. Gogoi, N., Sahu, P.P.: All-Optical Surface Plasmonic Universal Logic Gate Devices. Plasmon. 11, 1537-1542 (2016)

31. Moradi, M., Danaie, M., Orouji, A.A.: Design of all-optical XOR and XNOR logic gates based on Fano resonance in plasmonic ring resonators. Opt. and Quant. Electron. 51(5), 1-18 (2019)

32. Abdulnabi, S.H., Abbas, M.N.: All-optical logic gates based on nanoring insulator-metal-insulator plasmonic waveguides at optical communications band. J. of Nanophotonics. 13(1), 016009 (2019)

33. Swarnakar, S., Rathi, S., Kumar, S.: Design of All-Optical XOR Gate based on Photonic Crystal Ring Resonator. J. of Opt. Commun. 41(1), 1-6 (2017) 
34. Swarnakar, S., Kumar, S., Sharma, S., Performance analysis of all-optical full-adder based on two-dimensional photonic crystals. J. of Comp. Electron. 17, 1124-1134 (2018)

35. Kumar, S., Singh, L., Swarnakar, S.: Design of One-Bit Magnitude Comparator Using Nonlinear Plasmonic Waveguide. Plasmonics. 12, 369-375 (2016)

36. Rao, D.G.S., Swarnakar, S., Kumar, S.: Performance analysis of all-optical NAND, NOR, and XNOR logic gates using photonic crystal waveguide for optical computing applications. Opt. Engg. 59(5), 1-11 (2020)

37. Rao, D.G.S., Palacharla, V., Swarnakar, S., Kumar, S.: Design of all-optical D flip-flop using photonic crystal waveguides for optical computing and networking. Appl. Opt. 59(23) 7139-7143 (2020)

38. Swarnakar, S., Kumar, S., Sharma, S., Singh, L.: Design of XOR /AND gate using 2-D Photonic Crystal principle. Proc. of SPIE. 10130, 1-11 (2017)

39. Rathi, S., Swarnakar, S., Kumar, S.: Design of One-Bit Magnitude Comparator using Photonic Crystals. J. of Opt. Commun. 40(4), 1-5 (2017)

40. Swarnakar, S., Kumar, S., Sharma, S.: Design of All-optical Half-subtractor Circuit Device using 2-D Principle of Photonic Crystal Waveguides. J. of Opt. Commun. 40(3), 195-203 (2017)

41. Swarnakar, S., Kumar, S., Sharma, S.: All-Optical Half-Adder Circuit Based on Beam Interference Principle of Photonic Crystal. J. of Opt. Commun. 39(1), 13-17 (2016)

42. Taflove, A., Hagness, S.C.: Computational Electrodynamics: The Finite-Difference Time-Domain Method. Artech House, Boston London (2000)

43. Sharma, P., Kumar, V.D.: All-Optical Logic Gates Using Hybrid Metal Insulator Metal Plasmonic Waveguide. IEEE Photon. Tech. Lett. 30(10), 959-962 (2018)

44. Pal, A., Ahmed, M.Z., Swarnakar, S.: An optimized design of all-optical OR, XOR, and NOT gates using plasmonic waveguide. Opt. and Quant. Electron. 53(84), (2021)

45. Al-Musawi, H.K., Ali, K., Janabi, A., Al-abassi, S.A.W., Abusiba, N.A.H., Al-Fatlawi, N.A.H.Q.: Plasmonic logic gates based on dielectric-metal-dielectric design with two optical communication bands. Optik 223, 1-14 (2020) 
Figures

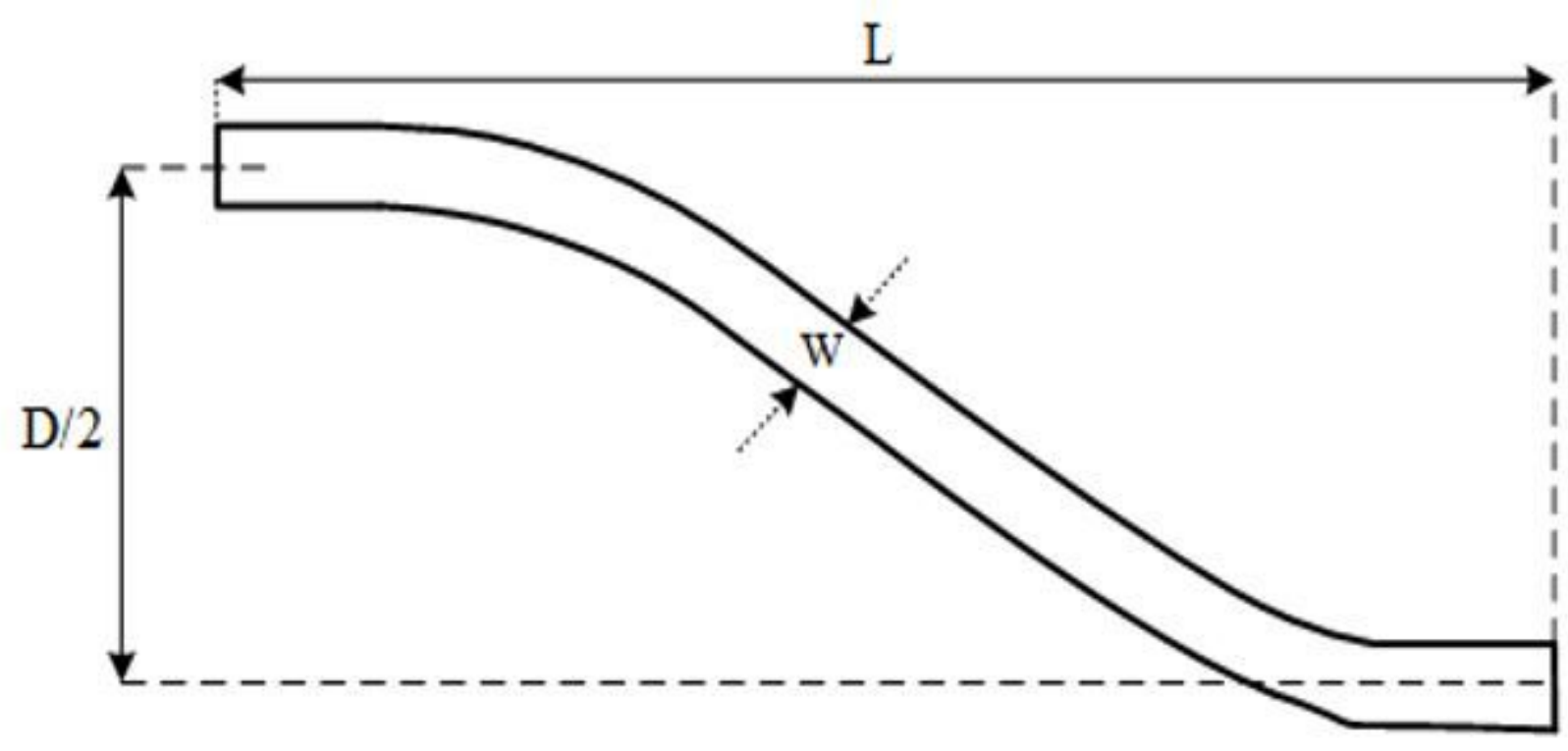

Figure 1

Structure of S-bend sine waveguide

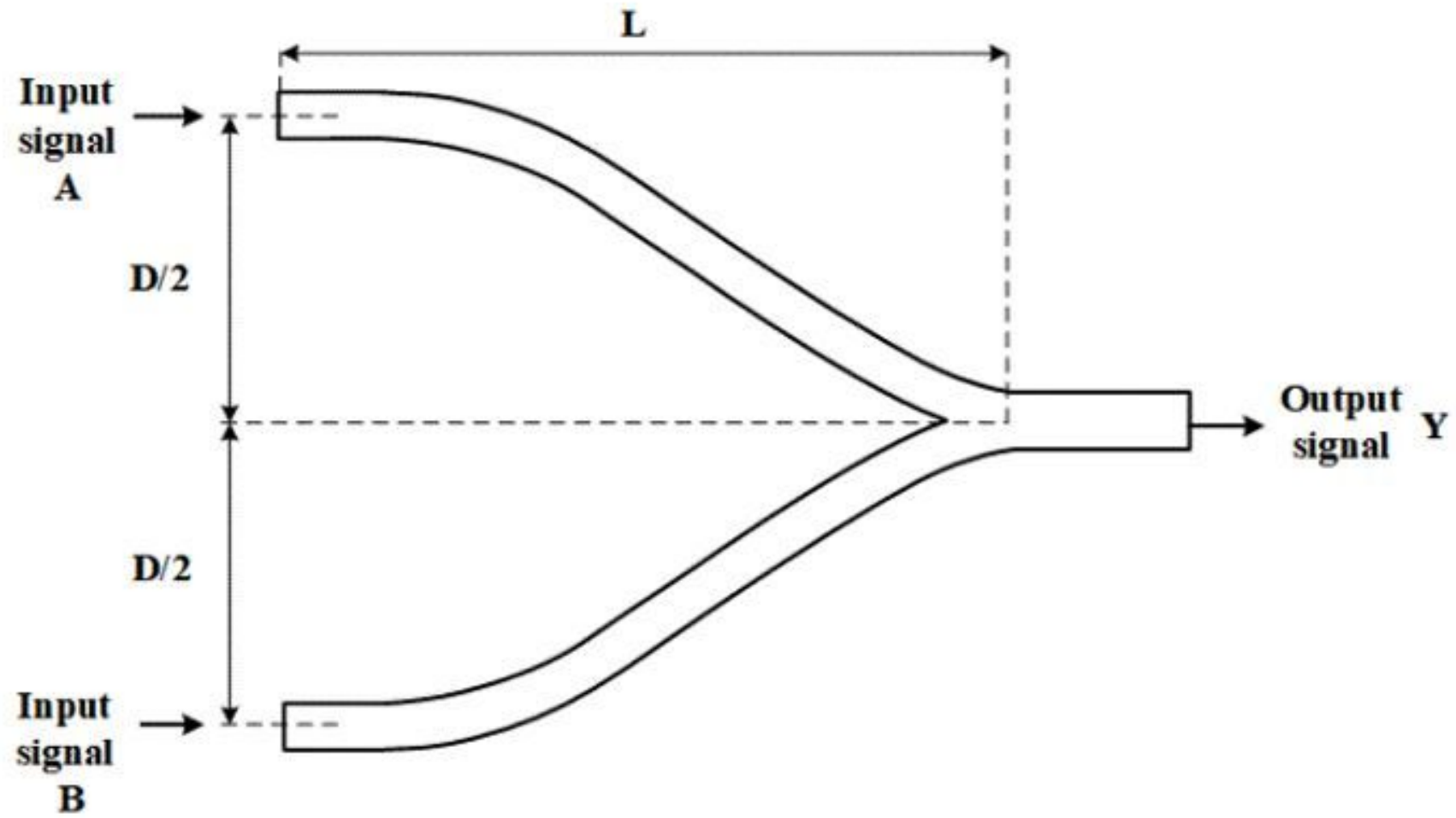

Figure 2 
Schematic of symmetric Y-combiner

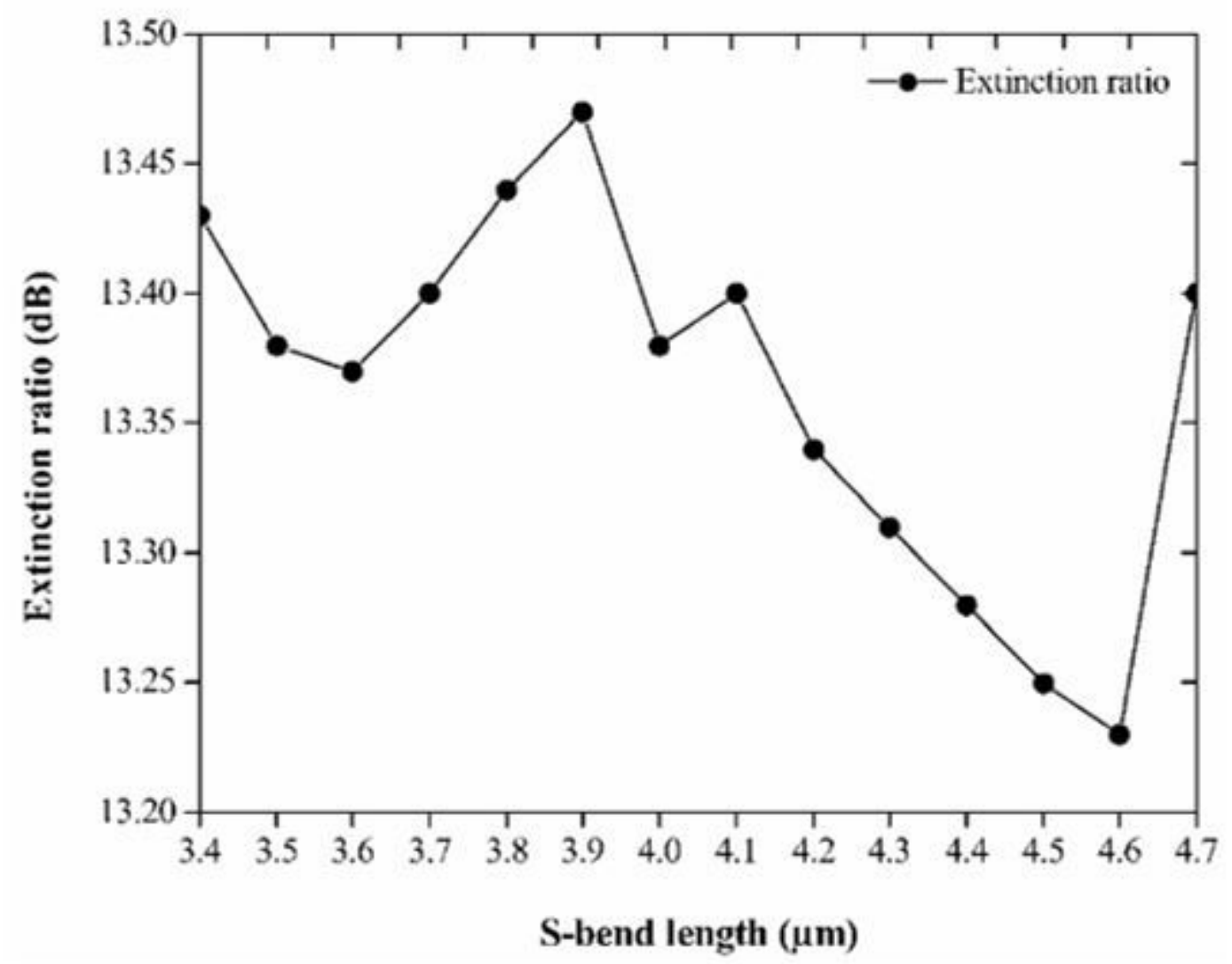

Figure 3

Plot of S-bend length versus extinction ratio at $D=3 \mu \mathrm{m}$ 


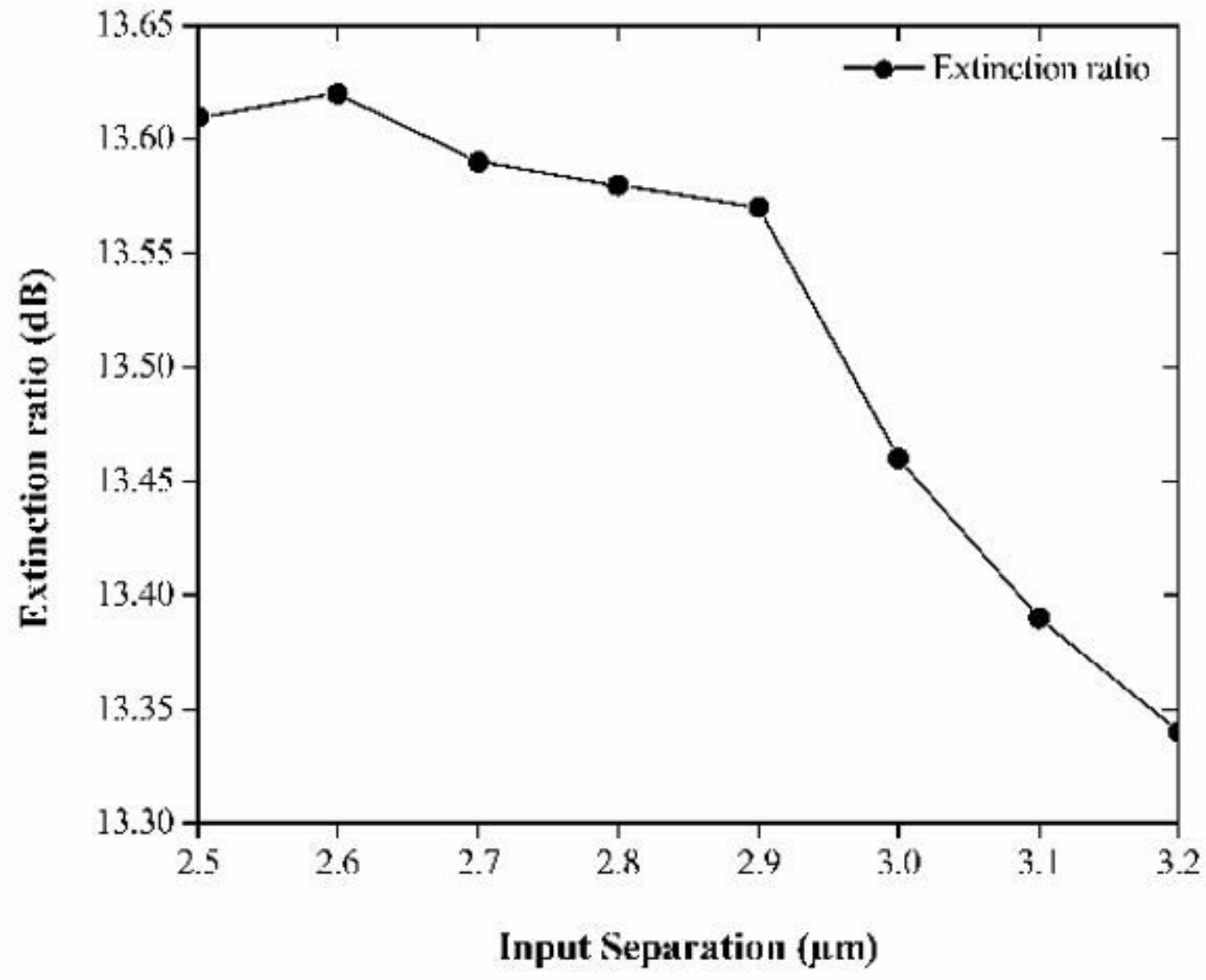

Figure 4

Plot of input separation gap versus extinction ratio at $L=3.9 \mu \mathrm{m}$ 


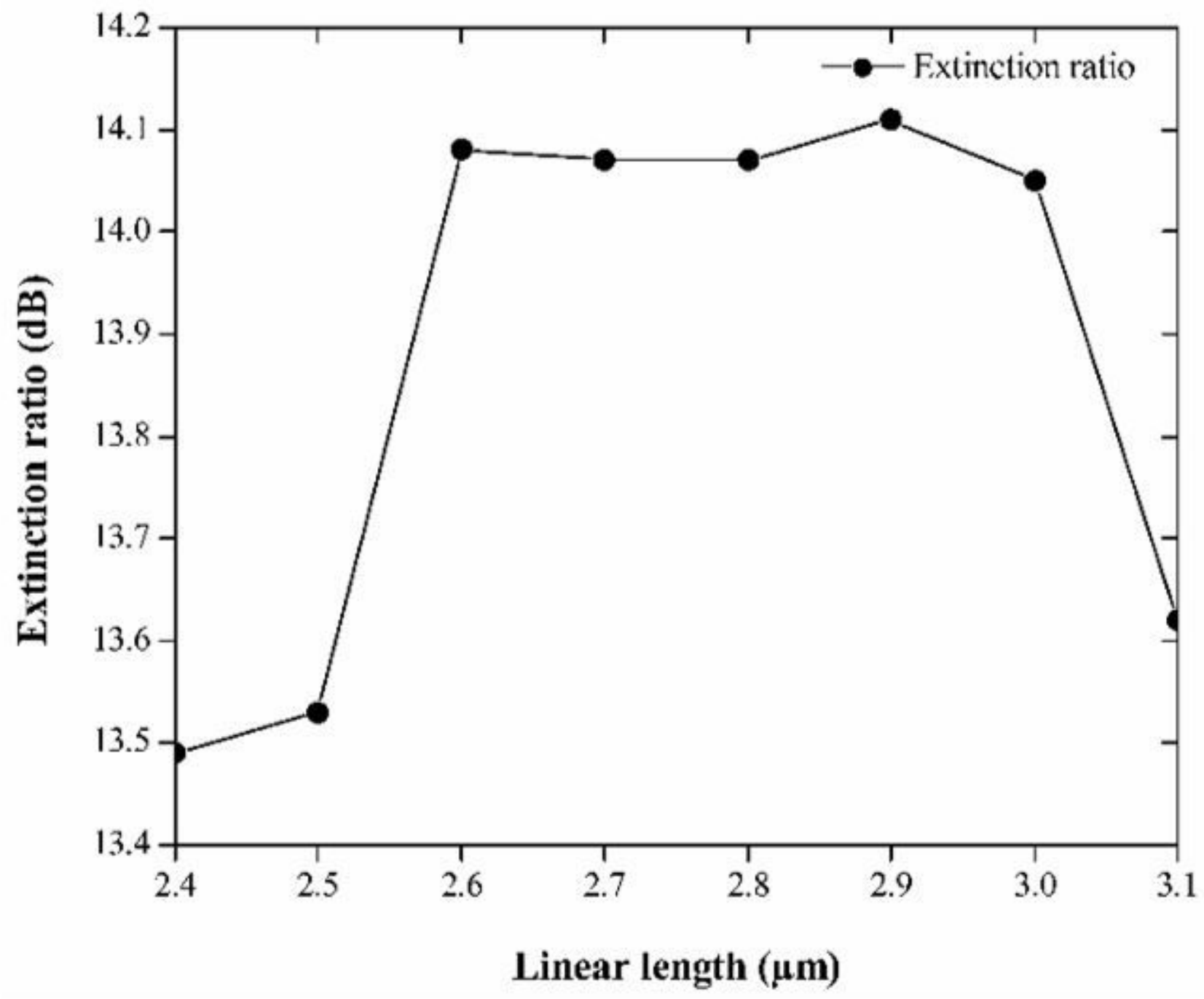

Figure 5

Plot of linear waveguide length versus extinction ratio at $L=3.9 \mu \mathrm{m}$ and $D=2.6 \mu \mathrm{m}$

Input Signal A

Input Signal B

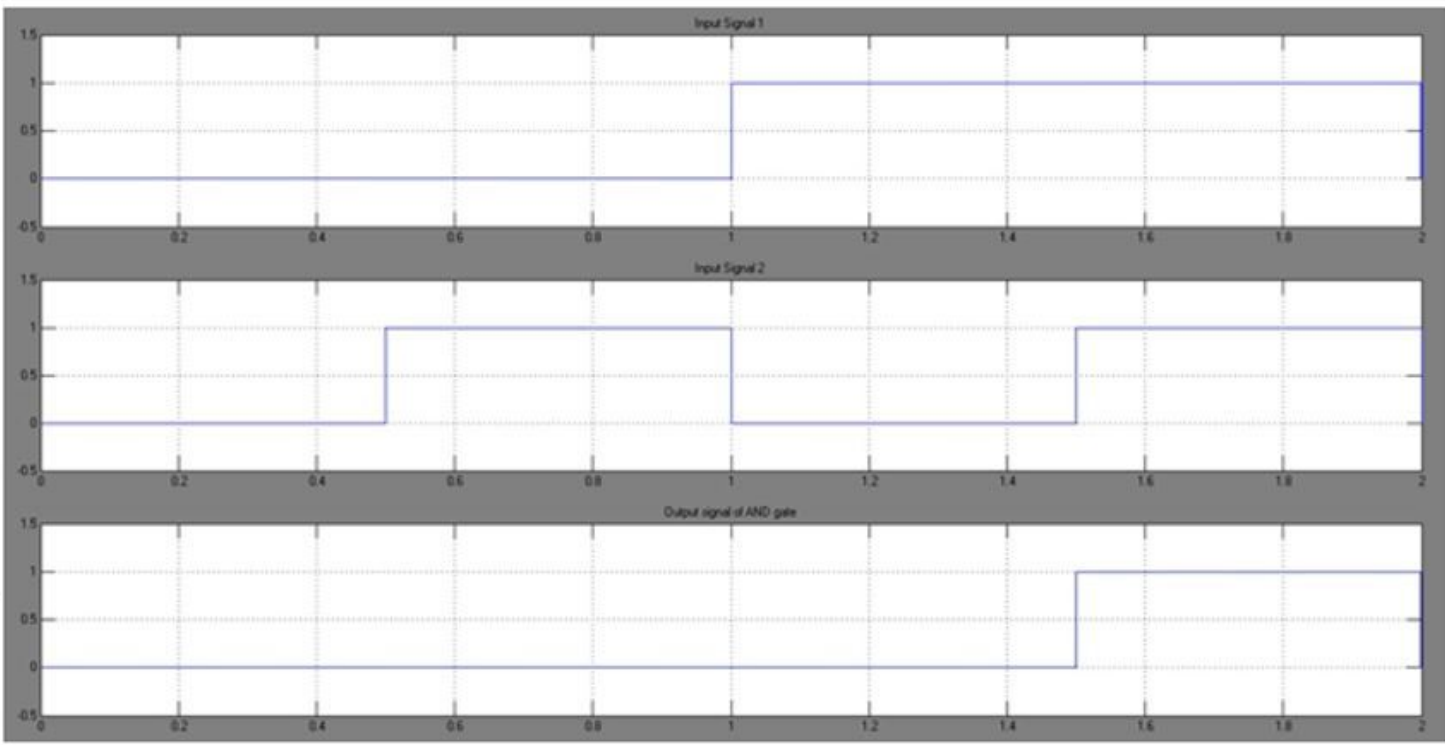


Figure 6

The timing diagram of AND gate using MATLAB

\section{INPUTS}

A B
OUTPUT

$\mathbf{Y}=\mathbf{A}$. B

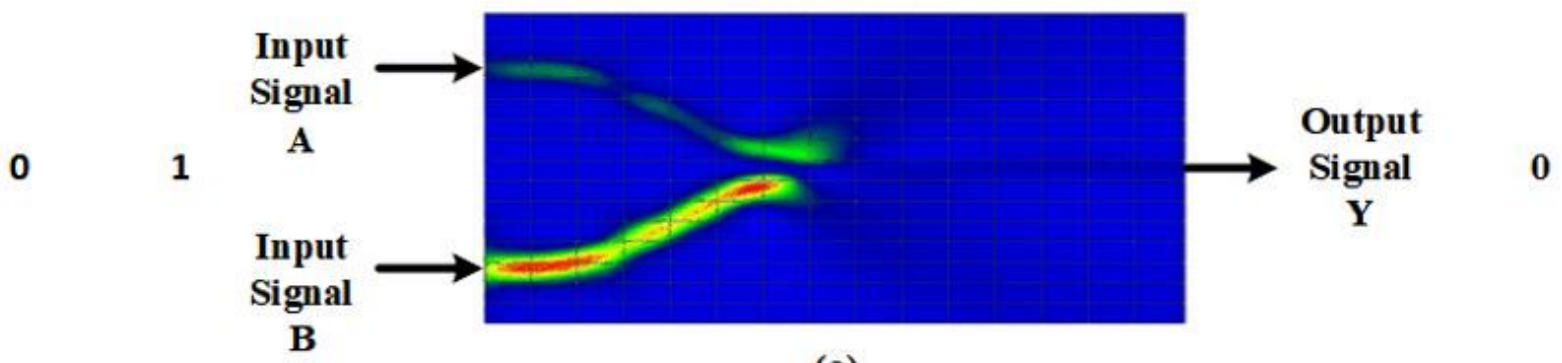

(a)

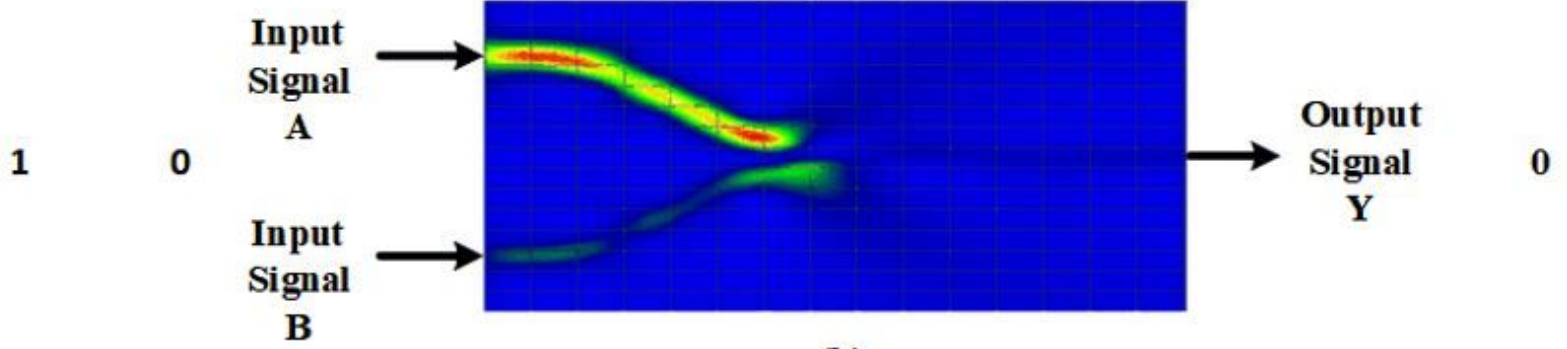

(b)

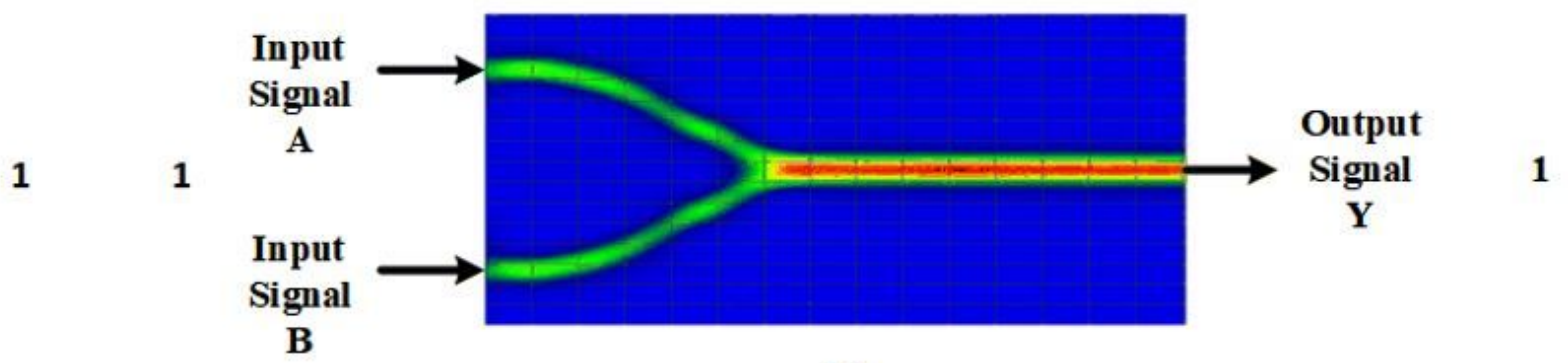

(c)

\section{Figure 7}

Light propagation through proposed AND gate for all combinations of input signals using FDTD method 